$\mathbb{T}$ periodica polytechnica

Chemical Engineering

$55 / 1(2011) 31,34$

doi: 10.3311/pp.ch.2011-1.06

web: http://www.pp.bme.hu/ch

(C) Periodica Polytechnica 2011

RESEARCH ARTICLE

\section{Sulfuric acid baking and leaching of spent sulfuric acid catalyst}

\author{
Abdulrahman Wahoud / Adel Alouche / Mohamedalkhaled Abdulbake
}

Received 2010-10-19

\begin{abstract}
Vanadium, iron and aluminum were recovered from the spent sulfuric acid catalyst with efficiency of $98 \%, 95 \%$ and $85 \%$, respectively by using low temperature sulphuric acid baking followed by leaching. The optimum baking conditions were four grams of concentrated sulfuric acid per ten grams of spent catalyst at $300{ }^{\circ} \mathrm{C}$ for two hours. Sulphuric acid baking followed by leaching was found to be the best and it is more effective in Iron and Aluminum dissolution. Sulfuric acid baking is expected to consume small amount of chemicals and generate much less waste effluents during the separation process of metals with alkali solutions. It is economically favorable, as it avoids us much more environmental contamination.
\end{abstract}

\section{Keywords}

Baking $\cdot$ Vanadium $\cdot$ Aluminum $\cdot$ Iron $\cdot$ Spent catalyst

\section{Acknowledgement}

The authors would like to express their thanks and appreciation to Albaath University for its help and encouragement to carry out this research. We are very grateful to General Fertilizer Company $(G F C) /$ Homs for supplying catalyst samples.

\footnotetext{
Abdulrahman Wahoud

Albaath University,, P.O. Box 77 Homs, Syria

e-mail: awahoud@yahoo.com
}

\section{Adel Alouche}

Mohamedalkhaled Abdulbake

Albaath University,, P.O. Box 77 Homs, Syria

\section{Introduction}

Catalytic processes have many industrial uses [1,2], which is increasing every day. The catalysts deactivate with time and when the activity of the catalyst declines below the acceptable level, it is usually regenerated and reused [3,4], but regeneration is not always possible [5, 6], and after a few cycles of regeneration and reuse, the catalyst activity may decrease to very low level and further regeneration may not be economically feasible. The spent catalysts are discarded as solid wastes [7, 8] and their contribution to environmental contamination is increasing every day. The hazardous nature of the spent catalysts is attracting the attention of environmental authorities in many countries and the environmental laws become more severe in recent years. Spent catalysts have been classified as hazardous wastes by the Environmental Protection Agency in USA [9, 10]. At the same time, most of these catalysts contain valuable metals ( $\mathrm{V}, \mathrm{Ni}, \mathrm{Mo}$, $\mathrm{Co}$, etc.) in the form of oxides or sulfides supported on carriers such as alumina, silica, etc. Recovery of these metals, many of which in turn consumed in carbon and stainless steel- making as an alloying agent to produce ferro-alloys and other valuable products, is an attractive option [11-13]. Hydrometallurgical processes to recover pure vanadium from sulfate solutions coming from leaching of spent catalysts were proposed by means of solvent extraction with primary aliphatic amine [14] or using organic phase containing di(2-ethylhexyl) phosphoric acid combined with tributyl phosphate [15]. Recent literature survey revealed that large number of hydrometallurgical processes proposed wide variety of reagents for leaching of spent catalysts. Several mineral acids and their combination in different concentrations were used in different processes [16-18]. Among the mineral acids, sulfuric acid leaching has certain economical and operational advantages [19]. Recovery of vanadium pentoxide from spent sulfuric acid catalysts was reported [20] using a three-step process consisting of acid leaching, oxidation and precipitation. Alkaline leaching is more selective for iron but dissolves some silica and is more costly in term of reagents [21]. However, in many other instances, leaching with strong mineral acids or alkaline reagents was found to be ineffective in completely dissolving the catalyst. So, some of alkalic roast- 

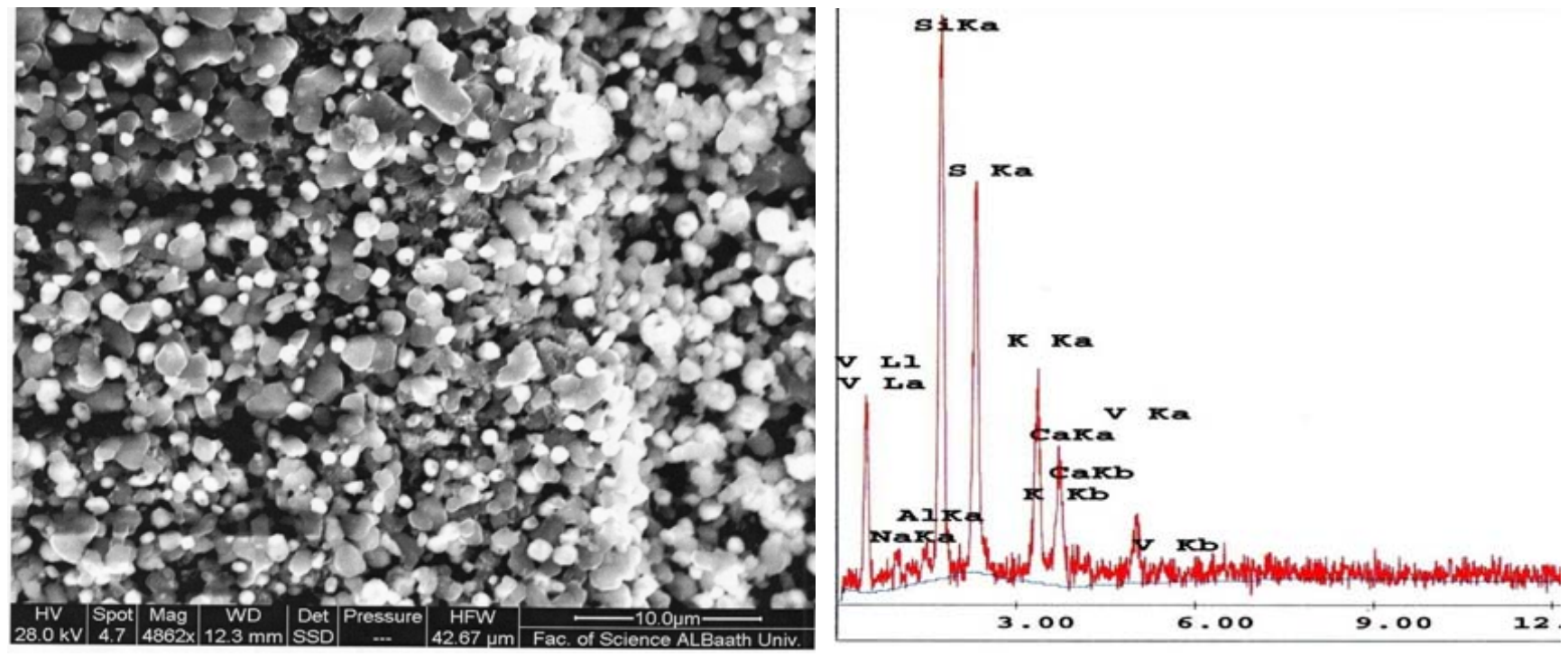

Fig. 1. The SEM image with EDX spectrum of the spent catalyst

ing processes were explored and higher dissolution was reported by using potassium bisulfate [22], but these processes consume large excess of the costly reagents and generate large quantities of liquid effluents in the down stream. Sulfuric acid baking is expected to be effective at comparatively lower temperature than alkalic roasting processes and could be lower acid consumption than direct sulfuric acid leaching. Therefore, the purpose of the present work is to explore an innovative sulfuric acid baking route for recovery and complete dissolving of metals in the spent catalyst.

\section{Experimental}

\subsection{Materials}

Spent catalyst used in the manufacture of sulphuric acid was supplied by the General Fertilizer Company GFC Homs /Syria. For consistency, the spent catalyst for all experiments was collected from one batch and grounded to a particle size between 1 and $2 \mathrm{~mm}$ since lower grain sizes did not improve leaching efficiencies in preliminary tests. Sulfuric acid used for baking and leaching and all other chemicals employed were of analytical grade.

\subsection{Procedures and apparatus}

Baking tests were carried out inside a muffle furnace (Carbolite). In each experiment $10 \mathrm{~g}$ of spent catalyst was mixed with suitable amount of concentrated sulfuric acid inside a $100 \mathrm{ml}$ porcelain crucible. All leaching tests were carried out in a beacher with a magnetic stirrer placed in a thermostat to control the temperature. All baked samples were leached with $100 \mathrm{ml}$ of $2 \%$ sulfuric acid solution at $100{ }^{\circ} \mathrm{C}$ for 1 hour. The mixtures were filtered with a vacuum filtrating unit. The samples were diluted and concentrations of metals $(\mathrm{V}, \mathrm{Fe}, \mathrm{Al})$ were determined by atomic absorption spectroscopy (AAS/Varian).

\section{Results \& discussions}

\subsection{Characterization of the spent catalyst}

SEM image of spent catalyst containing $4.5 \% \mathrm{~V}, 3.5 \% \mathrm{Al}$, $1.2 \% \mathrm{Fe}$ and $11.8 \%$ moisture is in Fig. 1 1 on the left. The average particle size was about $1 \mu \mathrm{m}$. The EDX spectrum on the right shows the metal ingredients of this catalyst. We note that both vanadium and iron have a good scattering on the alumina-silica support.

\subsection{Sulphuric acid leaching}

The leaching of spent catalyst with sulphuric acid can be represented by the following equations:

$$
\begin{aligned}
& \mathrm{V}_{2} \mathrm{O}_{5}+\mathrm{H}_{2} \mathrm{SO}_{4} \rightarrow\left(\mathrm{VO}_{2}\right)_{2} \mathrm{SO}_{4}+\mathrm{H}_{2} \mathrm{O} \\
& \mathrm{Fe}_{2} \mathrm{O}_{3}+3 \mathrm{H}_{2} \mathrm{SO}_{4} \rightarrow \mathrm{Fe}_{2}\left(\mathrm{SO}_{4}\right)_{3}+3 \mathrm{H}_{2} \mathrm{O} \\
& \mathrm{Al}_{2} \mathrm{O}_{3}+3 \mathrm{H}_{2} \mathrm{SO}_{4} \rightarrow \mathrm{Al}_{2}\left(\mathrm{SO}_{4}\right)_{3}+3 \mathrm{H}_{2} \mathrm{O}
\end{aligned}
$$

According to these equations and to the chemical composition of this spent catalyst mentioned above, less than 0.25 grams of concentrated sulphuric acid is enough for reacting with all the three metals contained by one gram of spent catalyst. The effect of sulphuric acid concentration on leaching efficiency of valuable metals $(\mathrm{V}, \mathrm{Fe}, \mathrm{Al})$ was studied by varying the concentration of the acid from 0.5 to $3 \mathrm{~mol} / \mathrm{l}$ and keeping other conditions constant (temperature $90{ }^{\circ} \mathrm{C}$, mixing time $90 \mathrm{~min}$, solid/liquid ratio $(\mathrm{S} / \mathrm{L}) 5 \%)$. The results are presented on Fig. 2 where the recovery yields of metals were plotted versus concentration of sulphuric acid. The results show that the acid concentration of about $2.5 \mathrm{M}$ is enough to dissolve about $90 \%$ of vanadium, while iron and aluminum dissolution seems to be only $60 \%$ and $50 \%$, respectively. Higher aluminum dissolution is possible by increasing the acid concentration but vanadium and iron dissolution tend to decrease. Moreover, higher acid concentration in the leaching stage results in more consumption of chemicals during the metal separation processes and it will make leaching solution highly viscous and difficult to filtrate.

The effect of mixing time and temperature on leaching ef- 
ficiency was studied with acid concentration $2.5 \mathrm{~mol} / \mathrm{l}$ and solid/liquid ratio (S/L) $5 \%$. The results are presented on Figs. 3 and 4 which show that both of mixing time and temperature have positive effect on leaching efficiency. It is clear that the efficiency increases by increasing the mixing time and temperature and it remains constant after one hour and $80{ }^{\circ} \mathrm{C}$.

\subsection{Sulphuric acid baking}

Since direct sulphuric acid leaching was found to be ineffective in iron and aluminum dissolution, sulphuric acid can be used more effective in metals dissolution through baking process which as expected converts metal oxides into soluble metal sulfates. All backed samples were furthermore treated by leaching with $100 \mathrm{ml}$ of $2 \%$ sulfuric acid solution under fixed conditions (temperature $100{ }^{\circ} \mathrm{C}$, mixing time 1 hour).

\subsubsection{Effect of sulphuric acid amount}

The effect of sulphuric acid amount on recovery efficiency of metals was investigated by adding different amount of sulphuric acid (1-8 g) to $10 \mathrm{~g}$ of spent catalyst sample keeping other conditions constant (baking temperature $300{ }^{\circ} \mathrm{C}$, baking time $2 \mathrm{~h}$ ). The results are presented on Fig. 5 in the form of recovery efficiency of metals versus added sulphuric acid amounts. The results show that four grams of acid are enough to dissolve about $98 \%$ of vanadium and more than $95 \%$ and $80 \%$ of iron and aluminum, respectively.

\subsubsection{Effect of baking temperature}

In order to study this effect, baking temperature was varied from $200{ }^{\circ} \mathrm{C}$ to $400{ }^{\circ} \mathrm{C}$ keeping other conditions constant (baking time $2 \mathrm{~h}$, sulphuric acid amount $5 \mathrm{~g}$ ). The results are plotted on Fig. 6. At first, the recovery efficiency increases by increasing the baking temperature, but it is clear that the efficiency decreases when the baking temperature increases above $300{ }^{\circ} \mathrm{C}$. This could be possibly due to the rate of evaporation of sulfuric acid exceeding the rate of sulfation of metal oxides.

\subsubsection{Effect of baking duration}

The effect of baking duration on recovery efficiency of metals was investigated by baking the $10 \mathrm{~g}$ spent catalyst at $300{ }^{\circ} \mathrm{C}$ with four grams of concentrated sulfuric acid for different time intervals. The results are shown in Fig. 7, which indicates that two hours baking time is enough for optimum metal dissolution.

\section{Conclusions}

Vanadium, iron and aluminum can be recovered from the spent catalyst with efficiency of $98 \%, 95 \%$ and $85 \%$ respectively by using sulphuric acid baking followed by leaching. The optimum baking conditions were four grams of concentrated sulfuric acid per ten grams of spent catalyst at $300{ }^{\circ} \mathrm{C}$ for two hours. Sulphuric acid baking followed by leaching was found to be the best because it consumes acid about four times less

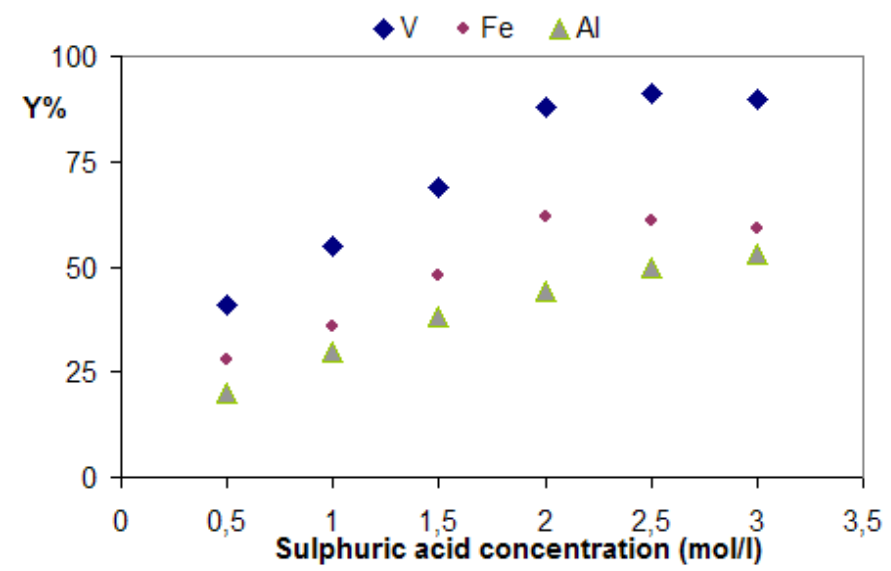

Fig. 2. The effect of sulphuric acid concentration on metal leaching yield ( $\mathrm{T}$ $=90{ }^{0} \mathrm{C}$, leaching time $=90 \mathrm{~min}, \mathrm{~S} / \mathrm{L}=1 / 10 \mathrm{~g} / \mathrm{ml}$ )

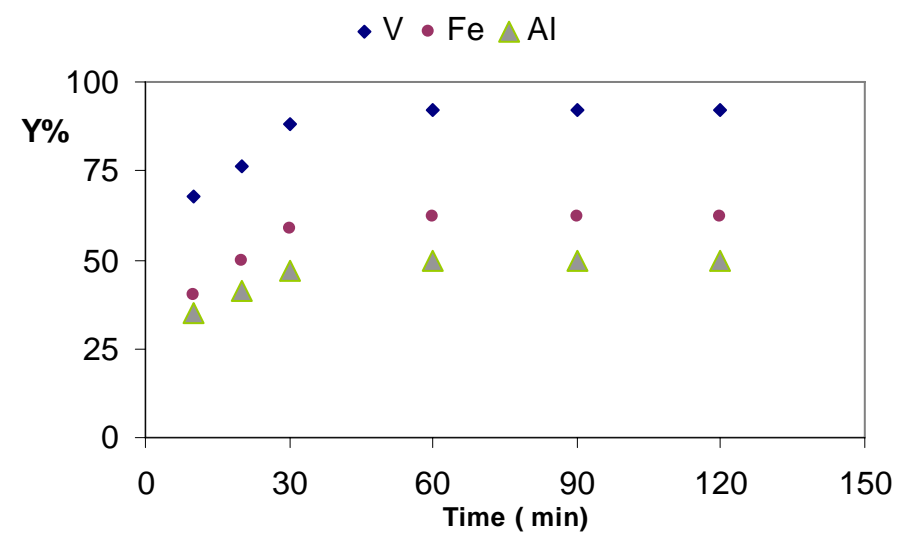

Fig. 3. The effect of mixing time on leaching yield $\left(\mathrm{T}=90^{0} \mathrm{C}\right.$, concentration of sulphuric acid $2.5 \mathrm{M}, \mathrm{S} / \mathrm{L}=1 / 10 \mathrm{~g} / \mathrm{ml}$ )

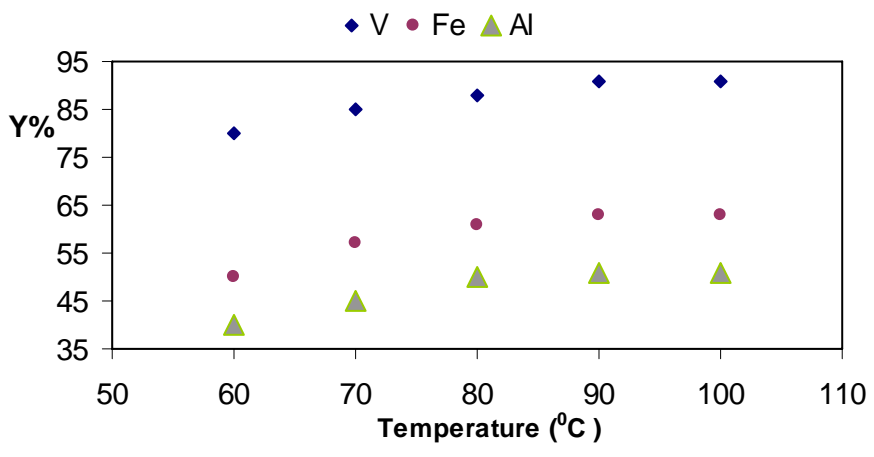

Fig. 4. The effect of temperature on leaching yield (mixing time $=90 \mathrm{~min}$, concentration of sulphuric acid $2.5 \mathrm{M}, \mathrm{S} / \mathrm{L}=1 / 10 \mathrm{~g} / \mathrm{ml}$ )

than direct sulphuric acid leaching process and it is more effective in iron and aluminum dissolution. Therefore, sulphuric acid baking is expected to consume small amount of chemicals and will generates much less waste effluents during the separation process of metals with alkali solutions. Therefore, it can be economically favorable, as well as it is accompanied much less environmental contamination. The scale-up of baking process needs further investigation, especially with respect to the structural material of baking device. 
$\bullet \mathrm{V} \bullet \mathrm{Fe} \triangle \mathrm{Al}$

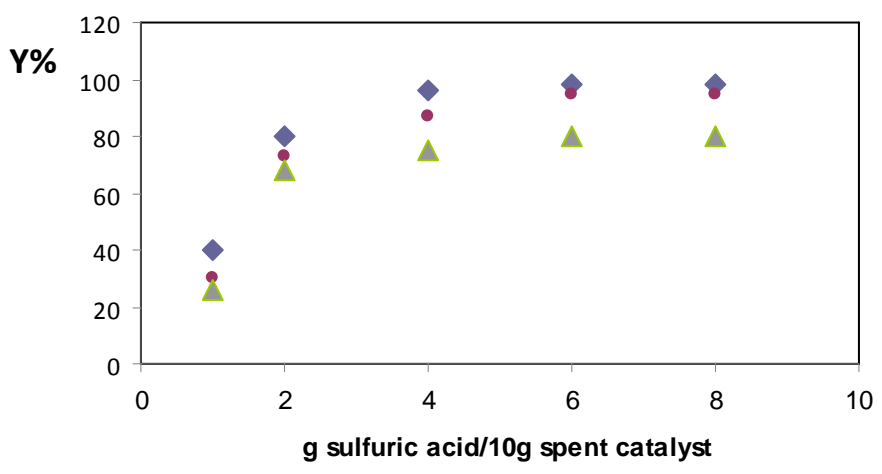

Fig. 5. The effect of sulphuric acid amount on recovery yield (baking time $=2 \mathrm{~h}, T=300{ }^{\circ} \mathrm{C}$ )

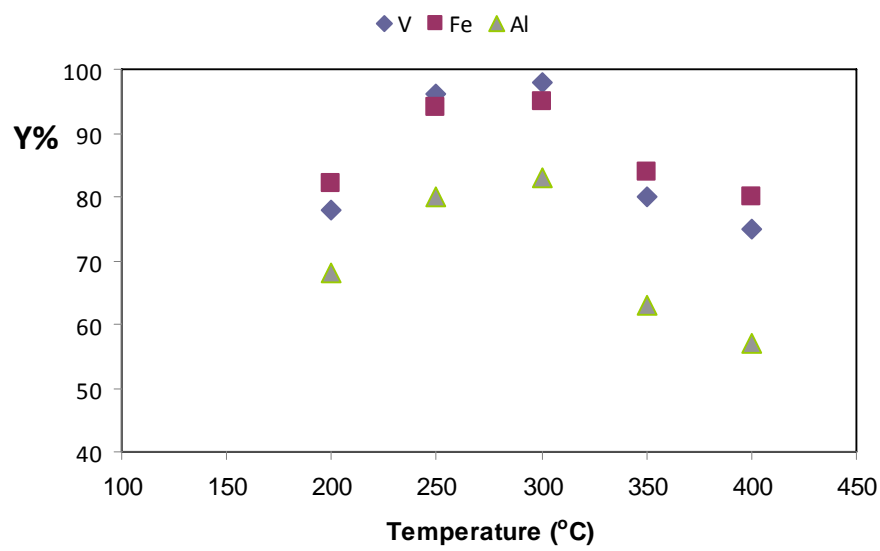

Fig. 6. The effect of baking temperature on recovery yield (baking time $=2 \mathrm{~h}$, sulphuric acid amount $=5 \mathrm{~g}$ )

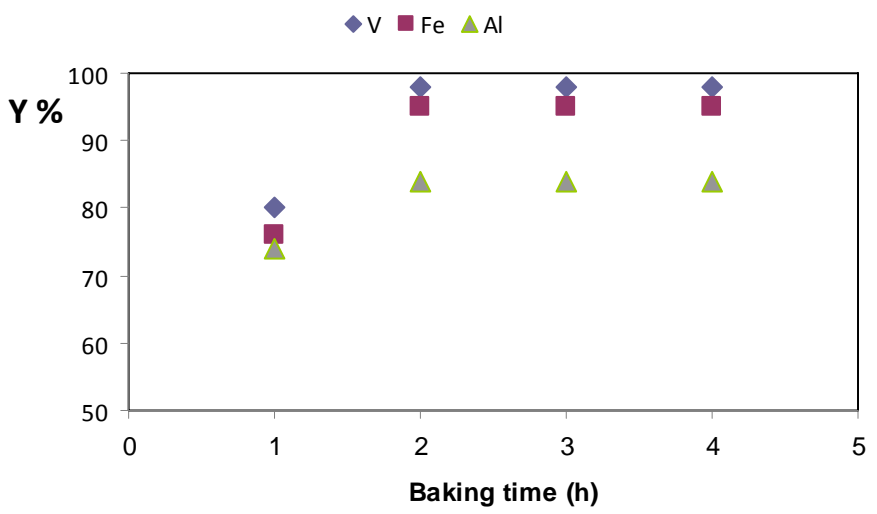

Fig. 7. The effect of baking time on recovery yield $\left(\mathrm{T}=300{ }^{0} \mathrm{C}\right.$, sulphuric acid amount $=5 \mathrm{~g}$ )

\section{References}

1 Brown C M, Johnston T C, Goelz G J, C.I.M.Bulletin, 1974.

2 Topose H, Clausen B S, Massoth F E, Hydrotreating catalysts-Science $\mathcal{E}$ Technology, Springer-Verlag, Berlin, 1996.

3 Clifford R K, Spent catalyst handling, 1997.

4 Chang T, Spent catalyst options, Oil Gas J. 19 (1998), 1979-1998.

5 Furimsky E, Spent refinery catalysts: environment, safety and utilization, Catal. Today 30 (1996), 223-286.

6 Marafi M, Stanislaus A, Spent catalyst waste management: a review part I, Resour. Conserv. Recycling 52 (2008), 859-873.

7 Trimm D I, The regeneration or disposal of deactivated heterogeneous catalysts, Appl. Calal. A Gen. 212 (2001), 153-160.
8 Marafi M, Stanislaus A, Preparation of heavy oil Hydrotreating catalysts from spent residue hydroprocessing catalysts, Catal. Today 130 (2008), 421428.

9 Hazardous waste management system, Vol. 68, 2003. United Stated Environmental Protection Agency (USEPA), Federal Register.

10 Rapport D, Spent hydroprocessing catalysts listed as hazardous wastes, Hydrocarbon Process 79 (2000), 11-22.

11 Kar B B, Datta P, Misra V N, Spent catalyst: secondary source for molybdenum recovery, Hydrometallurgy 72 (2004), 87-92.

12 Chen Y, Feng Q, Shao Y, Zhang G, Ou L, Lu Y, Research on the recycling of valuable metals in spent $\mathrm{Al}_{2} \mathrm{O}_{3}$-based catalyst, Miner. Eng. 19 (2006), 94 97.

13 Hayatt D E, Value recovery from spent alumina-based catalyst, 1987. USP No.4657745.

14 Lozano L Juan D, Solvent Extraction of polyvanadates from sulfate solutions by PRIMENE 81R, Solvent Extraction and Ion Exchange 19 (2001), no. 4, 659-676.

15 Otternum H, Strandell E, Solvent Extraction of vanadium (IV) with DEHPA and TBP, Solvent Extraction conference, CIMM, 1979, pp. 21.

16 Lai Y, Lee W, Metal recovery from hydrodesulfurization catalysts using a combined acid leaching and electrolysis process, J. Hazard Mater. 154 (2008), 588-594.

17 Lima T S, Campos P S, Afonso J C, Metal recovery from spent hydrotreatment catalysts in fluoride bearing medium, Hydrometallurgy 80 (2005), 211219

18 Inoue K, Pingwei Z, Tsuyama H, Recovery of $\mathrm{V}, \mathrm{Mo}$, Ni and Co from spent hydrodesulfurization catalysts, Prepr. ACS Div. Pet. Chem. 38 (1993), no. 1, 77-80.

19 Valverde I M, Paulino J F, Afonso J C, Hydrometallurgical route to recover Mo, Ni, Co and Al from spent hydrotreatment catalysts in sulfuric acid medium, J. Hazard Mater. 160 (2008), 310-317.

20 Wahoud A, Khorfan S, Reda Y, Recovery of vanadium pentoxide from spent catalyst used in the manufacture of sulphuric acid, Periodica Polytechnica Ser. Chem. Eng. 45 (2001), no. 2, 131-137. 0

21 Ho E M, Kyle J, Lallence S, Muir D M, Recovery of vanadium from spent catalysts and alumina residues, IMM Hydrometallurgy'94, Chapman \&Hall, London, 1994, pp. 1105-1121.

22 Busnardo R G, Busnardo N G, Salvato G N, Afonso J C, Processing of spent $\mathrm{Ni}, \mathrm{Mo}$, and $\mathrm{Co}-\mathrm{Mo} / \mathrm{Al}_{2} \mathrm{O}_{3}$ catalysts via fusion with $\mathrm{KHSO}_{4}$, J. Hazard Mater. B 139 (2007), 391-398. 